\title{
SAUdAÇĀo PROFERIDA PELO PROFESSOR GERALdO ATALIBA AO NOVO TITULAR, PROFESSOR REGIS FERNANDES DE OLIVEIRA
}

Excelentíssimo Senhor Diretor Professor Antônio Junqueira de Azevedo, Excelentíssimo Senhor Professor Carlos Mário Velloso, Eminente Ministro do Supremo Tribunal Federal, cuja presença honra esta Faculdade e abrilhanta esta sessão solene,

Senhor Professor Régis Fernandes de Oliveira, homenageado desta noite, Colegas da Congregação,

Senhoras e Senhores,

Senhores alunos,

Aos cinqüenta anos de idade ingressa no doutoral desta velha e sempre nova Academia o ilustre Professor Régis Fernandes de Oliveira. Esta sessão é uma boa oportunidade para nos lembrarmos que a Universidade nasceu na Idade Média, da associação de jovens sequiosos de aprender, que se cotizavam e se organizavam e saiam a contratar doutores para exercerem a função de ensinar-lhes. Daí a expressão ou palavra doutor, aquele que sabe, a expressão docere, aquele que transmite o que sabe.

Os professores eram recrutados mediante contrato pelos alunos e, naqueles tempos, nos primórdios da Universidade (Bolonha, Paris, Coimbra), os reitores eram alunos, os diretores eram alunos; eles eram os interessados no ensino; eles cativavam os professores; eles buscavam quem lhes viesse trazer a sabedoria para poderem então crescer intelectual e, por que não dizer, espiritualmente também.

A Universidade evolui ao longo dos tempos, sofre todas as influências das idéias dominantes no mundo até que, após um processo lento, paulatino, árduo, pesado, sofrendo as influências de todas as contingências sociais da evolução econômica, espiritual e política do Ocidente, chega a esta feição que temos hoje.

A nossa Universidade, Professor Régis, na qual hoje Vossa Excelência ingressa no topo da carreira universitária, corresponde de maneira excelente à proposta republicana que se contém nas nossas Constituições e que está 
reafirmada nesta belíssima, nesta admirável, eu diria - com licença e com o apoio, eu tenho certeza, do ilustre ministro e constitucionalista Carlos Velloso, do Professor Celso Antonio Bandeira de Mello, do Professor Tércio Ferraz - esta Constituição é uma das mais invejáveis peças político-juridicas que a humanidade já pôde conceber.

Não seria necessário nem tempo há para se mencionar seus méritos. Basta considerar quem a ataca e como ela é atacada. Isto é o suficiente para quem tem um pouco de bom-senso, serenidade, prudência, senso de observação, saiba dar valor a esta Carta, que escreve, entre seus preceitos, que o ensino público será universalmente aberto e gratuito. Estes são preceitos que são novamente reiterados por este magnífico diploma constitucional.

Disse eu que esta Universidade realiza excelentemente as propostas que a Carta Constitucional contém: a República, afirmada no artigo primeiro da Constituição, reiterada, sublinhada, repetida, reforçada, prestigiada por inúmeros preceitos contidos ao longo do texto constitucional. A República é o regime em que o povo é o dono do Poder Público. E o povo, portanto, integrado ou feito pelo conjunto dos cidadãos, é o dono do Estado, titular da soberania e exerce as suas atribuições pelos seus delegados, por ele eletivamente investidos, para prestarem o serviço público na mais alta e lata expressão, pois na Constituição brasileira ensinar na escola pública é exercer serviço público.

É o que vem aqui fazer Régis Fernandes de Oliveira, somando as suas generosas e magníficas forças a de seus colegas da Congregação. Realizamos uma Universidade em que o aluno, como integrante do povo, desfruta, por desígnio constitucional, do ensino gratuito e onde os professores são recrutados por um processo de seleção, mediante concursos públicos de títulos e de provas, não só para o ingresso na carreira docente mas para ascender a cada degrau desta longa, penosa e árdua carreira, que foi percorrida integralmente por Régis Fernandes de Oliveira.

Este, senhores professores, senhoras e senhores, excelentíssimo senhor Diretor, é um momento magno, é um momento solene para a Universidade.

Régis Fernandes de Oliveira assume a culminância da cátedra nesta Faculdade, nesta sesquicentenária instituição, que tem sabido triunfar sobre todos os embates e adversidades que ao longo do tempo se lhe foram oferecendo. Sucede, no exercício da cátedra de Direito Financeiro, a Antonio Roberto Sampaio Dória, ilustre professor, cujo nome não pode ser pronunciado sem o maior respeito e sem a 
maior demonstração de afeto e de consideração pelo que deixou para a Faculdade, para a legião de ex-alunos e para nós, pessoalmente, a mim e a Régis Fernandes de Oliveira, que o sucede.

Antes de aqui iniciar ou prosseguir a sua carreira, Régis contribuiu, com suas notórias qualidades docentes, na Universidade Católica de São Paulo, onde realizou cursos de pós-graduação, um excelente mestrado, um brilhante doutoramento, sob a orientação do eminente Professor Celso Antonio Bandeira de Mello. Depois vem para esta Faculdade, faz a sua livre-docência e, coisa singular entre nós na Faculdade, é o único docente da atualidade que teve a glória de exercer função e de ter o título de professor adjunto em dois Departamentos ao mesmo tempo, o Departamento de Direito Econômico-Fincanceiro e o Departamento de Filosofia do Direito.

Esta trajetória que começa na Universidade Católica de São Paulo e aqui vem encontrar a sua culminância - toda ela marcada por concursos públicos de títulos e de provas - acompanhou uma trajetória paralela que Régis desenvolveu na atividade profissional de magistrado, iniciada em 1970, aonde também ingressou graças à magnífica Constituição e a nossa tradição constitucional, mediante concurso público de títulos e de provas, galgando cada degrau da carreira da magistratura em concursos, sempre passando por mérito, jamais por antiguidade.

Desta longa e fecunda atividade como magistrado em que Régis se fez exemplar, se fez líder, eu queria salientar, ilustre Ministro e Professor Carlos Mário Velloso, um momento que foi culminante e antecipatório. Régis Fernandes de Oliveira era juiz da Fazenda Pública na Capital de São Paulo. Isto - já se vão quase vinte anos - e se depara com uma ação popular em que, neste clima cujos estertores ainda vivemos, de lascidão, conivência, tolerância, os assaltos aos cofres públicos, o descaramento com que se manejam as funções públicas e os cargos públicos, já começava a ganhar as dimensões que afinal alcançaram os momentos dos idos de 91 e 92, que foram tão apaixonadamente acompanhados pela nacionalidade. Este processo encontra, vamos dizer, o seu grande desabrochar durante a ditadura militar em que o silêncio da imprensa, a conivência dos parlamentares, a omissão do Poder Judiciário de modo geral, com exceções, foram fazendo medrar estas sementes que agora começam a explodir e a apodrecer aos nossos olhos. Régis Fernandes de Oliveira era juiz da Fazenda Pública e encontra-se diante de uma ação popular. Isto está publicado e eu tenho que dar o nome aos bois - o Tribunal 
de Contas do Estado de São Paulo, tendo sete integrantes, pelo voto de quatro deles, concede a um cidadão contagem de tempo de aposentadoria fazendo incluir, no tempo de serviço público prestado, dez anos, sei lá quantos, tempo em que figurou na lista do júri e que, portanto se considerava à disposição do Tribunal do Júri. $O$ cidadão, descaradamente, solicita isso; e mais descaradamente ainda, o Tribunal, por quatro a três, lhe dá esta contagem de tempo. E este cidadão moço, de forma fraudulenta, com esta interpretação comprometida, consegue a aposentadoria. Proposta ação popular, cai nas mãos do juiz Régis Fernandes de Oliveira, que não teve a menor dúvida em julgar procedente a ação, anular a aposentadoria, condenar o interessado a devolver aos cofres públicos - e aí o sentido antecipatório de Régis praticando há quase vinte anos atrás um ato jurisdicional, que mais nos lembraria os magistrados italianos que na atualidade combatem as máfias oficiais e oficiosas que corromperam a Itália. Estas máfias, as quais ainda não nos livramos no Brasil, embora eu seja otimista, começamos agora, pelo menos, a identificá-las para denunciá-las. E Régis, então um jovem juiz da Capital, no clima ditatorial em que vivíamos, sem nenhuma cobertura de imprensa e ainda sem ter manifestado aquelas qualidades que depois o transformaram neste líder, inclusive entre os magistrados, condena os quatro conselheiros do Tribunal de Contas que votaram, afirmando ou concedendo aquela contagem de tempo flagrantemente repugnante, imoral e ilegal.

Isso é uma demonstração do que já era possivel àquele tempo e este exemplo lamentavelmente não foi seguido. Já era possivel naquele tempo ser-se corajoso, cumprir-se o direito, cumprir-se o dever altiva e altaneiramente e fazer com que prevalecesse o espírito da Constituição e o sentido dos institutos jurídicos mais sagrados, decorrentes das exigências republicanas.

Este jovem juiz, se tivesse sido seguido por outros, teria evitado que o Brasil chegasse ao momento em que chegou há um ano e pouco atrás, quando a juventude foi obrigada a pôr-se nas ruas de cara pintada para, na omissão das instituições, na omissão dos órgãos incumbidos e encarregados oficialmente de reprimir os abusos, pregar em praça pública. Aqueles jovens em massa, dando exemplo ao povo brasileiro, pregavam que era preciso de uma vez por todas cumprir-se o mais elementar dos preceitos jurídicos e éticos: não roubarás! Dentro da lei, cumprindo rigorosamente a função jurisdicional, atendeu à indignação popular, realizou o espírito do Direito, deu eficácia à Constituição e, numa decisão exemplar do ponto de vista da técnica jurídica, prestou republicanamente a 
jurisdição que é devida pelos membros do Judiciário ao povo, especialmente mediante este instituto notável que é a ação popular.

Foi antecipatório e, acredito, que hoje valeria a pena estudar algumas das suas decisões - mas tempo não há para mencioná-las - para que se conheça o perfil deste Professor que agora acolhemos na Faculdade com tanta honra e com tanta satisfação.

Aqui chega o Professor Régis de Oliveira, sustentando tese sobre as receitas públicas não-tributárias para o concurso à titularidade. Ousadia extrema adotar este tema, quando não há no Brasil literatura a respeito. Admirável trabalho que realiza o Professor Régis, quando consegue do deserto arrancar fontes que pudessem matar a sua sede e a de seus leitores e discípulos de saber, de conhecer a literatura, as doutrinas a respeito dessa temática tão árida, tão abandonada e esquecida entre os nossos publicistas, especialmente no campo da sua especialidade.

É uma tese original, inovadora, avançada. Basta lê-la sem preconceitos. Extremamente lúcida. Esta tese é a expressão da personalidade de Régis Fernandes de Oliveira. Ela é tão afirmativa, tão corajosa que, ao lê-la, ainda que não se concorde ou que se possa discordar de uma ou outra afirmação, o leitor se infunde de profundo respeito por quem a escreveu. Antes disso, já produzira copiosa obra, traduzida em livros; isto para não mencionar todas as sentenças e acórdãos que evidentemente elaborou ao longo de sua laboriosa vida de magistrado, como os artigos, as conferências, os seminários de que participou. Dentre esses trabalhos, poderiam ser mencionados os seguintes livros : $O$ Ato Administrativo; Licitação; Funcionário Estadual e seu Estatuto; Delegação Administrativa; Lacuna e Sistema Normativo; Infrações e Sanções Administrativas, que tive ocasião de citar ainda esta semana num parecer, Taxas de Polícia, Jurisprudência de Direito Tributário, Manual de Direito Financeiro, A Cobrança da Divida Ativa da Fazenda Pública. Todos os grandes temas do Direito Público, do Direito Constitucional, do Direito Administrativo, do Direito Financeiro, que é a cátedra que agora ocupa. Todos estes temas, repassados ao longo dos anos com mão madura e visão lúcida, estão estampados nesta obra, submetida ao julgamento de todos nós.

Líder inato e empreendedor, o criador Régis Fernandes de Oliveira revela-se também um líder político e, ainda jovem, juiz de Primeira Instância, é eleito presidente da Associação Paulista de Magistrados. Pela primeira vez na 
história desta vetusta, tradicional e austera instituição que desde a sua fundação e até então só pudera e só concebera possivel fazer presidente seu algum desembargador, alguém que está na culminância dạ carreira judiciária!

Régis, juiz de Primeira Instância, numa batalha empolgante de ser acompanhada e assistida, e agora lembrada, faz-se pela primeira vez na história, presidente da Associação Paulista de Magistrados. Tal foi o seu trabalho, o seu desempenho que, muito breve, terminada esta função, é eleito presidente da Associação Brasileira de Magistrados, onde teve a oportunidade de fecundar esta Associação; e o ilustre Ministro Carlos Velloso, sócio que é da Associação, certamente testemunhará o quão laborioso, inventivo, criador e incentivador foi o presidente Régis Fernandes de Oliveira no exercício desta função. E tão produtivo e fecundo foi, que logo depois é eleito presidente da Federação Latinoamericana de Magistrados. E se mais não fez, senhores professores, é porque não há ainda uma associação mundial de magistrados e também porque Régis, prevalecendo-se de um preceito constitucional, a meu ver profundamente equivocado, aposentou-se como magistrado e já, portanto, não poderia exercer essa função, para prejuizo dos magistrados e prejuizo de todos nós.

Não há tempo senhor Diretor, Professor Antonio Junqueira de Azevedo, para falarmos a respeito do currículo, da biografia, de todas as ricas facetas do professor Régis Fernandes de Oliveira. Por isso, a mim me cabe simplesmente encerrar, formulando ao Professor Régis, em nome da Congregação, dois votos: um, o de que não esmoreça, mas que nos traga o seu espírito, a sua combatividade, a sua engenhosidade, para o seio desta Faculdade, fecundando-a e renovando-a. E o segundo voto, que a sua trajetória política, que a sua vocação de homem público, possam conciliar-se com o desejo que temos de gozar de seu convívio e aproveitar os frutos da sua inteligência e do seu trabalho!

Muito obrigado. 